\title{
Purificación Del Aire Ambiente Interior En La Fábrica De Productos Lácteos “Quesos Latacunga”, Cotopaxi, Ecuador
}

\author{
Agustín Leiva Pérez, \\ Ely F. Sacón Vera, \\ Escuela Superior Politécnica de Manabí, Ecuador \\ Rodolfo Najarro Quintero, \\ Azucena Elizabeth Bernal, \\ Universidad Tecnológica de Querétaro, Mexico \\ David W. Moreira Vega, \\ Joffre A. Andrade Candell, \\ Escuela Superior Politécnica de Manabí, Ecuador
}

doi: 10.19044/esj.2017.v13n15p47 URL:http://dx.doi.org/10.19044/esj.2017.v13n15p47

\begin{abstract}
The purification of the internal ambient air of the "Latacunga Cheese" factory was studied by the application of ozone. It is an energetic oxidizing agent which is able to kill the microorganisms present in the medium where it is found. It is applied in its appropriate doses with the aim of purifying the air environment of the workshop. The concentrations of fungi and bacteria found before the application of ozone were higher than that allowed by the Spanish legislation "UNE 100012 Hygiene of systems". Among the fungi identified were Aspergillus sp., Penicilium sp., Scopulariopsis sp., Fusarium sp., and Cladosporium sp. The major bacteria identified were Staphylococcus sp., Streptococcus sp., Bacillus sp., Streptomyces sp., and Enterobacter agglomerans. The main material used for the treatment of indoor air with ozone was a SEFILTRA purifier. This purifier, however, generates an ozonated air flow rate of $2 \mathrm{dm} 3 /$ min with an ozone concentration in air of $9.5 \mathrm{~g} / \mathrm{m} 3$. This means it has an ozone charge of about $1.14 \mathrm{~g} / \mathrm{hr}$. A High Efficiency Particle Arresting (99.995\%) filter was used to measure microbial air content before and after treatment. After an hour of application of ozone, the reduction of fungi was sufficient to ensure that its presence was complied with the maximum limit established in the legislation in question. However, this does not happen with bacteria which needs about 25 minutes more to conclude which is the same as for fungi.
\end{abstract}


Keywords: Purification, inside environmental air, ozone, bacteria, mushroom, oxidizer agent

\section{Resumen}

Se estudió la purificación del aire ambiente interior de la fábrica de "Quesos Latacunga" mediante la aplicación de ozono, como agente oxidante enérgico capaz de matar los microorganismos presentes en el medio en que se encuentre, en dosis apropiadas con el objetivo de purificar el aire ambiente del taller. Las concentraciones de hongos y bacterias encontradas antes de la aplicación del ozono fueron superiores a lo permitido por la normativa española "UNE 100012 Higienización de sistemas". Entre los hongos identificados se encontraron Aspergillus sp., Penicilium, sp., Scopulariopsis sp., Fusarium sp. y, Cladosporium sp. La principales bacterias identificadas fueron Staphylococcus sp., Streptococcus sp., Bacillus sp., y Streptomyces sp. y, Enterobacter agglomerans. Los materiales principales empleados para el tratamiento del aire interior con ozono fueron un purificador SEFILTRA, que genera un caudal de aire ozonizado de 2 $\mathrm{dm}^{3} / \mathrm{min}$, con una concentración de ozono en el aire de $9,5 \mathrm{~g} / \mathrm{m}^{3}$; es decir, una carga de ozono de alrededor de $1,14 \mathrm{~g} / \mathrm{h}$; mientras que para la medición del contenido microbiano en el aire antes y después del tratamiento, se utilizó un filtro HEPA (High Efficiency Particle Arresting, 99,995\%). Al transcurrir una hora de aplicación de ozono la reducción de hongos, fue suficiente como para que su presencia cumpliera con el límite máximo establecido en la normativa considerada, sin embargo, eso no ocurre con las bacterias, necesitándose unos 25 minutos más para poder concluir lo mismo que para los hongos.

Palabras clave: Purificación, aire ambiente interior, ozono, bacteria, hongo, agente oxidante

\section{Introducción}

La contaminación ambiental ha pasado, desde hace años, a tener una atención prioritaria por parte de científicos, tecnólogos y autoridades que gestionan la producción de los bienes y servicios necesarios para la vida sobre el planeta; esta gestión antes se desarrollaba con bases en insuficiencias en cuanto a lo sostenible y sustentable, en cuanto al ambiente en el que se ejecutan.

La protección de los bienes agua, aire y suelo se ha convertido en el principal objeto de observancia en cualquier actividad que en estos o con estos se desarrolle. Rodríguez (2003) reportó el uso la ozonización en la potabilización del agua de consumo humano, explicando la generación y 
destrucción del ozono residual. Muchos trabajos se han realizado sobre la industria y la contaminación de los mencionados bienes ambientales $\mathrm{y}$, precisamente en este estudio, se atiende a los problemas de contaminación del aire de ambientes de trabajo, donde, la función ambiental principal es la preservación de la calidad del aire que respiran los trabajadores encargados de la producción, particularmente en la industria láctea, donde se producen alimentos por acción de microorganismos, principalmente, como lo son, quesos, yogurt y otros. Los purificadores de aire mediante oxígeno activado (ozono) son muy eficientes para remover olores y contaminaciones microbiológicas, ácaros, bacterias, moho... (Engelberg, 2014).

En la producción de queso se puede optar por la adición de:

- Cultivos de bacterias productoras de ácido láctico.

- Cultivos de hongos o bacterias específicas para quesos de características especiales.

Estos organismos pueden ser expelidos al entorno y producir la contaminación biológica del aire ambiente en la fábrica. Los olores molestos son provocados por la descomposición de productos en devolución, por los Riles generados en el proceso productivo y cuando los equipos no se lavan con una frecuencia adecuada. Un buen manejo facilita su control. Por otra parte, el almacenamiento de quesos o su derretimiento (melting), puede provocar también olores desagradables. Además de los olores desagradables, bacterias, hongos en el aire, también, con cierta frecuencia pululan insectos que pululan en el lugar, particularmente las moscas (Ang, Tade \& Wang, 2007).

En la industria donde se realizó la investigación fue necesaria la aplicación de ozono a unos $211 \mathrm{~m}^{3}$ de volumen, es decir, un área de $12 \mathrm{~m}$ de largo, 8 de ancho y 2,20 m de altura, en el que se producen varios tipos de quesos. Los trabajadores que laboran en el mencionado taller, están continuamente expuestos a la inhalación de microorganismos, percibiendo olores indeseables y soportando la molestia e insanidad de insectos.

\section{Materiales y métodos}

Para la medición del contenido microbiano en el aire ambiente bajo estudio, antes y después de la aplicación del tratamiento con ozono, se utilizó un filtro HEPA (High Efficiency Particle Arresting), es decir, un Recogedor de Partículas de Alta Eficiencia, tipo H14, que exhibe un 99,995\% de eficiencia de retención de partículas en ámbitos locales cerrados, cuyo tamaño sea de al menos $0,3 \mu \mathrm{m}$, como es el caso de la mayoría de los microorganismos dañinos al tracto respiratorio humano.

Se utilizó para el tratamiento del aire interior con ozono, no dañino por su inestabilidad (Elvis \& Ekta, 2011, un purificador SEFILTRA, que cuenta con un generador de ozono y una turbina de alto rendimiento que 
garantiza una rápida eliminación de virus, bacterias, esporas, hongos del medio ambiente y una mayor oxigenación del espacio a tratar, proporcionando un ambiente fresco, casi libre de microorganismos. Las características del equipo fueron las siguientes:

- Caudal de aire ozonizado $=2 \mathrm{dm}^{3} / \mathrm{min}$

- $\quad$ Concentración de ozono en el aire $=9,5 \mathrm{~g} / \mathrm{m}^{3}$

- $\quad$ Generación o carga de ozono $1,14 \mathrm{~g} / \mathrm{h}$

- Voltaje: $110 \mathrm{~V} / 220 \mathrm{~V}$, según datos técnicos.

- Potencia: $100 \mathrm{~W}$.

El muestreo para aislamiento de bacterias en el aire, se realizó en agar nutriente, en su preparación se colocaron $23 \mathrm{~g}$ de agar nutriente en 1000 $\mathrm{cm}^{3}$ de agua destilada se le agregó en un vaso de precipitado (beaker) con capacidad de $2000 \mathrm{~cm}^{3}$, se homogenizó la mezcla mediante un agitador magnético. Posteriormente se dejó enfriar el medio a $50{ }^{\circ} \mathrm{C}$ para luego medir el $\mathrm{pH}$ nivelando el mismo a 7,2; después se sometió a esterilización en autoclave durante 15 minutos a $121{ }^{\circ} \mathrm{C}$ de temperatura (15 psi de presión). Finalmente el medio estéril se dispensó en placas de petri estériles de $90 \mathrm{~mm}$ $(9 \mathrm{~cm})$ de diámetro, a razón de $10 \mathrm{~cm}^{3}$ por placa.

El muestreo para aislamiento de hongos en el aire, se realizó en agar Saboraud, para su preparación se colocó $63 \mathrm{~g}$ de agar nutriente en $1000 \mathrm{~cm}^{3}$ de agua destilada en un vaso de precipitado con capacidad de $2000 \mathrm{~cm}^{3}$, se homogenizó la mezcla en un agitador magnético. Posteriormente se dejó enfriar el medio a $50{ }^{\circ} \mathrm{C}$ para luego medir el pH ajustando el mismo a 6,0; después se sometió a esterilización en autoclave por 15 minutos a $121^{\circ} \mathrm{C}$ de temperatura ( 15 psi de presión). Finalmente al medio estéril se le agregó una solución de gentamicina a razón de $50 \mathrm{ppm} / \mathrm{dm}^{3}$, y se dispensó en placas de petri estériles de $90 \mathrm{~mm}$ de diámetro $10 \mathrm{~cm}^{3}$ de medio respectivo.

La obtención de muestras biológicas del aire se realizó en los puntos designados, mediante el método de sedimentación, el cual consistió en colocar 10 placas de petri, distribuidas uniformemente, las cuales permanecieron abiertas y expuestas a una altura estándar de $1,80 \mathrm{~m}$ del piso; durante 30 minutos en el sitio a muestrear, preparadas con medio patrón en agar nutriente y Sabouraud para aislamiento de bacterias y hongos respectivamente (Borrego, 2005; Borrego, Pons, \& Perdomo, 2005; y Solórzano \& Vera, 2014), posteriormente fueron selladas con parafina y rotuladas, indicando el lugar, fecha y hora de muestreo.

Las placas fueron trasladadas en congelación a los laboratorios del Centro de Servicios Técnicos y Transferencia Tecnológica Ambiental (LABCESTTA, acreditación No. OAEE LE 2C 06 - 008), localizado en áreas de la Escuela Superior Politécnica de Chimborazo (ESPOCH), de la ciudad de Riobamba donde se incubaron en las cajas de petri en su respectivo medio de cultivo específico, durante un periodo de 24 horas a una 
temperatura de $35 \pm 2{ }^{\circ} \mathrm{C}$ para las bacterias y a 72 horas a una temperatura de $24 \pm 2{ }^{\circ} \mathrm{C}$ para hongos. Una vez concluida la incubación de las placas, se contaron las colonias fúngicas y bacterianas emergentes en los medios de cultivo y se determinaron las unidades formadoras de colonia por $\mathrm{m}^{3}$ de aire $\left(\mathrm{UFC} / \mathrm{m}^{3}\right)$, teniendo en cuenta la ecuación descrita por Omeliansky (Ministerio de la Industria Pesquera, 1987; Borrego, 2005; y Borrego, Pons \& Perdomo, 2005).

Dónde:

Número de $\frac{U F C}{\mathrm{~cm}^{3} \text { de aire }}=($ Número de colonias $)($ Factor $K)$

Número de colonias, equivale a la media total de las colonias que se contabilizaron por depósito.

Factor $K=80$, pues es el factor que se emplea para placas Petri de 9 cm de diámetro, como las que aquí se emplearon en los muestreos.

\section{Resultados y discusión}

En las Tabla y Figura No. 1, se presentan y representan los principales resultados obtenidos sobre concentraciones de bacterias y de hongos en el aire ambiente de la fábrica bajo estudio, según los datos entregados por el laboratorio acreditado referido anteriormente.

Tabla No. 1. Concentraciones en Unidades Formadoras de Colonias por cada metro cúbico de aire muestreado antes de la aplicación del ozono.

\begin{tabular}{|c|c|c|}
\hline CONCENTRACIÓN & Hongos $\left(\mathrm{UFC} / \mathrm{m}^{3}\right)$ & Bacterias $\left(\mathrm{UFC} / \mathrm{m}^{3}\right)$ \\
\hline Máxima & 898 & 1175 \\
\hline Mínima & 763 & 878 \\
\hline Media & 832 & 1010 \\
\hline
\end{tabular}

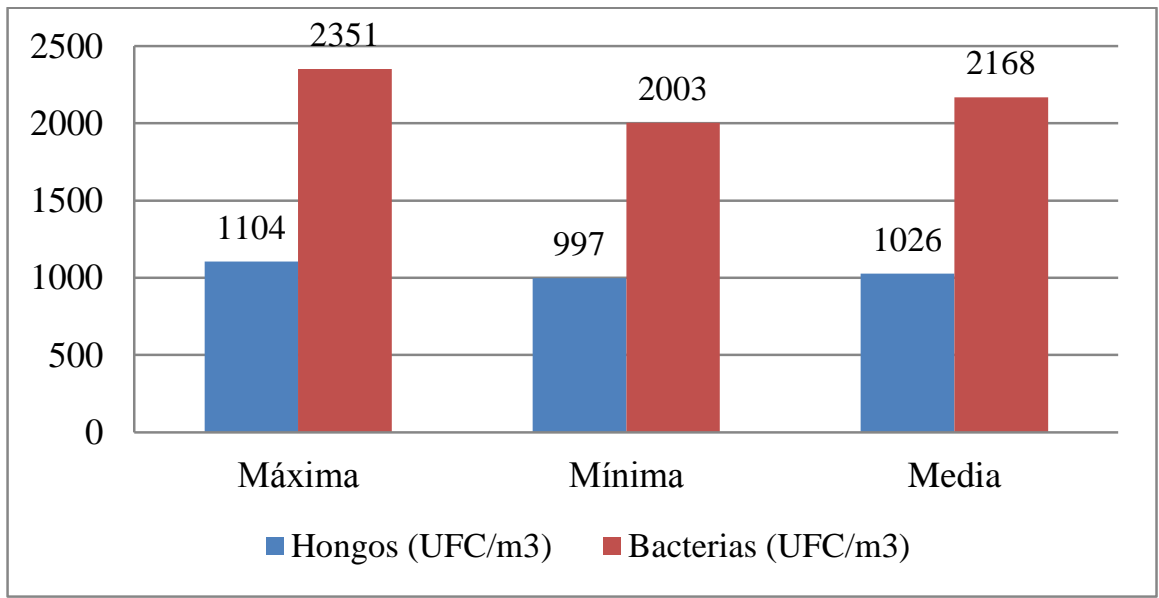

Figura No. 1. Concentraciones en Unidades Formadoras de Colonias por cada metro cúbico de aire muestreado antes de la aplicación del ozono. 
Entre los hongos identificados se encontraron Aspergillus sp., Penicilium, sp., Scopulariopsis sp., Fusarium sp. y, Cladosporium sp. La principales bacterias identificadas fueron Staphylococcus sp., Streptococcus sp., Bacillus sp., y Streptomyces sp. y, Enterobacter agglomerans.

Considerando los valores reportados en la Tabla 1 y gráfica de la figura de igual numeración y, los límites establecidos para bacterias y hongos en el aire, según la normativa española UNE 100012 Higienización de sistemas (PROQUIMES S.A. División Ambiente, 2005), se establece que tanto hongos como bacterias se encuentran en las cercanías o por encima del límite de $800 \mathrm{UFC} / \mathrm{m}^{3}$. Mucho más crítica la no conformidad ambiental en el caso de las bacterias que en el de los hongos.

A continuación se presentan las Figuras desde la 2 hasta la 10, donde se evidencia el comportamiento de las concentraciones de hongos y bacterias al incrementarse el tiempo de aplicación de ozono. Se denota una reducción continua de las concentraciones de microorganismos al incrementarse los tiempos de aplicación del agente oxidante desinfectante.

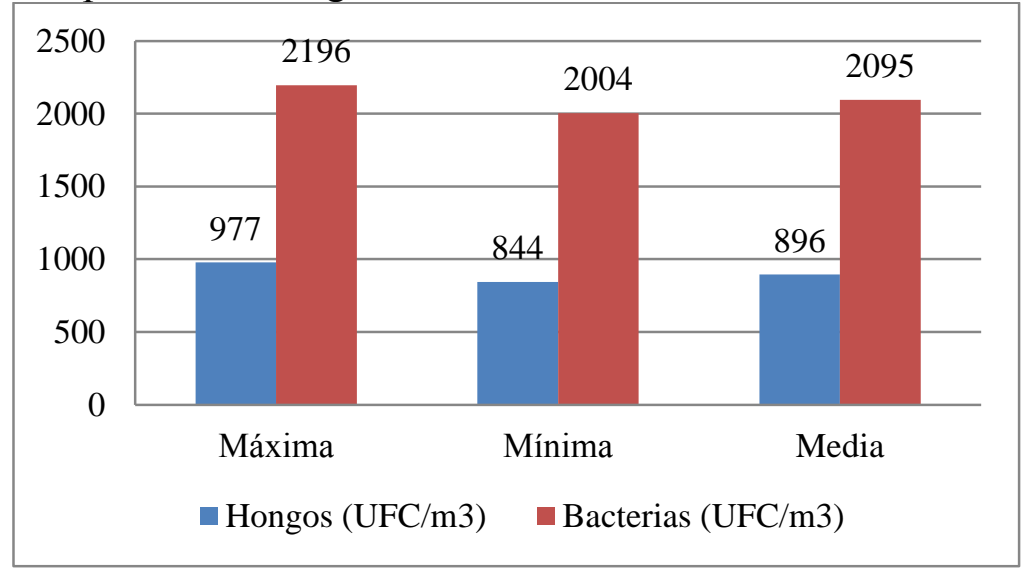

Figura No. 2. Concentraciones en Unidades Formadoras de Colonias por cada metro cúbico de aire muestreado como respuestas a 0,25 horas de aplicación de ozono.

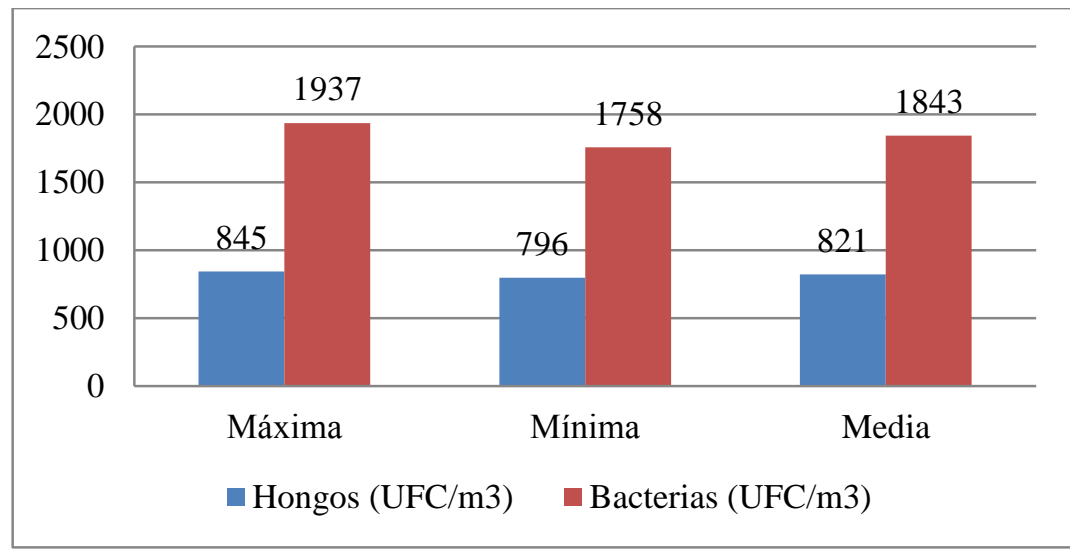


Figura No. 3. Concentraciones en Unidades Formadoras de Colonias por cada metro cúbico de aire muestreado como respuestas a 0,50 horas de aplicación de ozono.

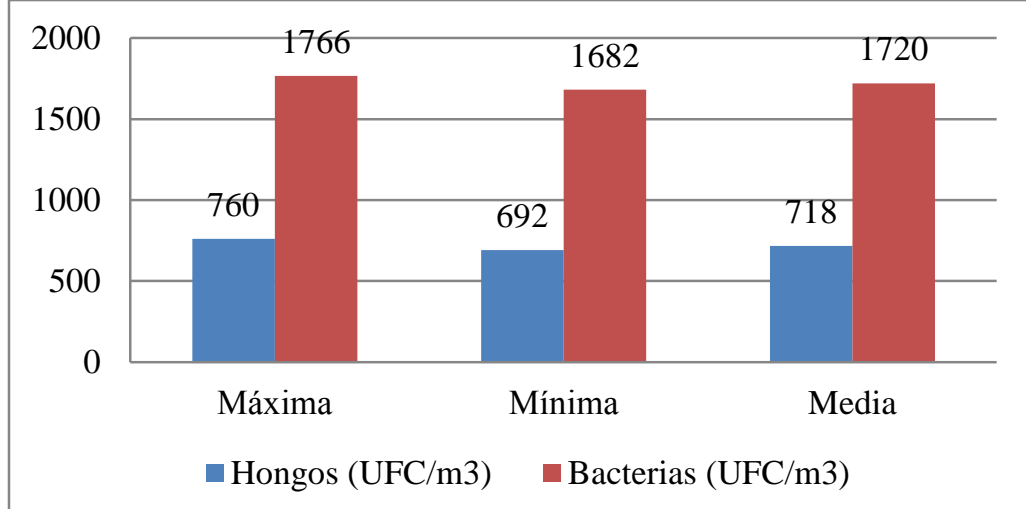

Figura No. 4. Concentraciones en Unidades Formadoras de Colonias por cada metro cúbico de aire muestreado como respuestas a 0,75 horas de aplicación de ozono.

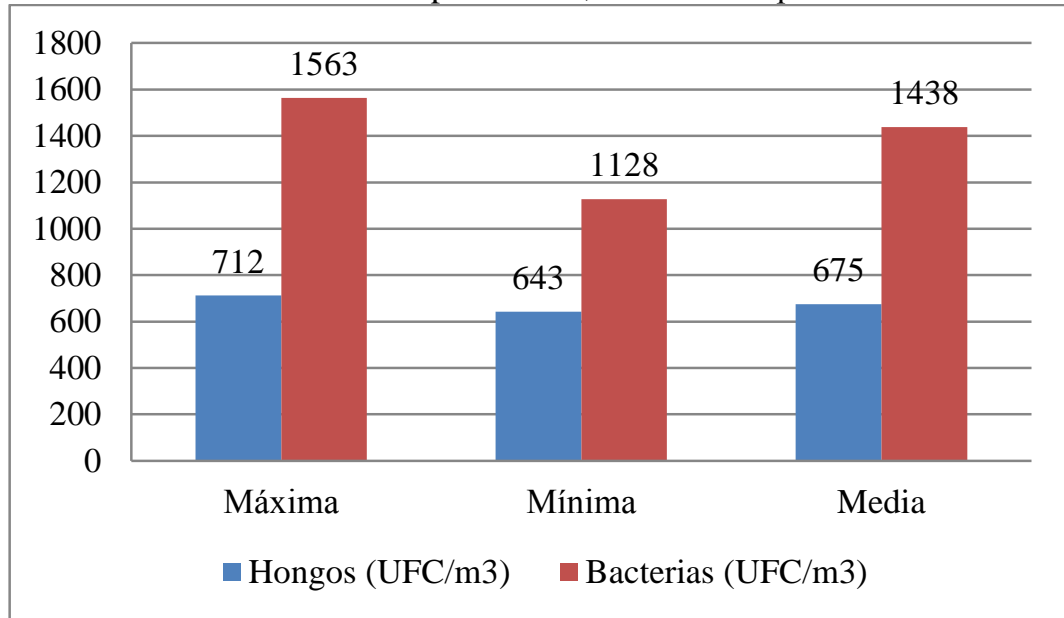

Figura No. 5. Concentraciones en Unidades Formadoras de Colonias por cada metro cúbico de aire muestreado como respuestas a 1,00 hora de aplicación de ozono.

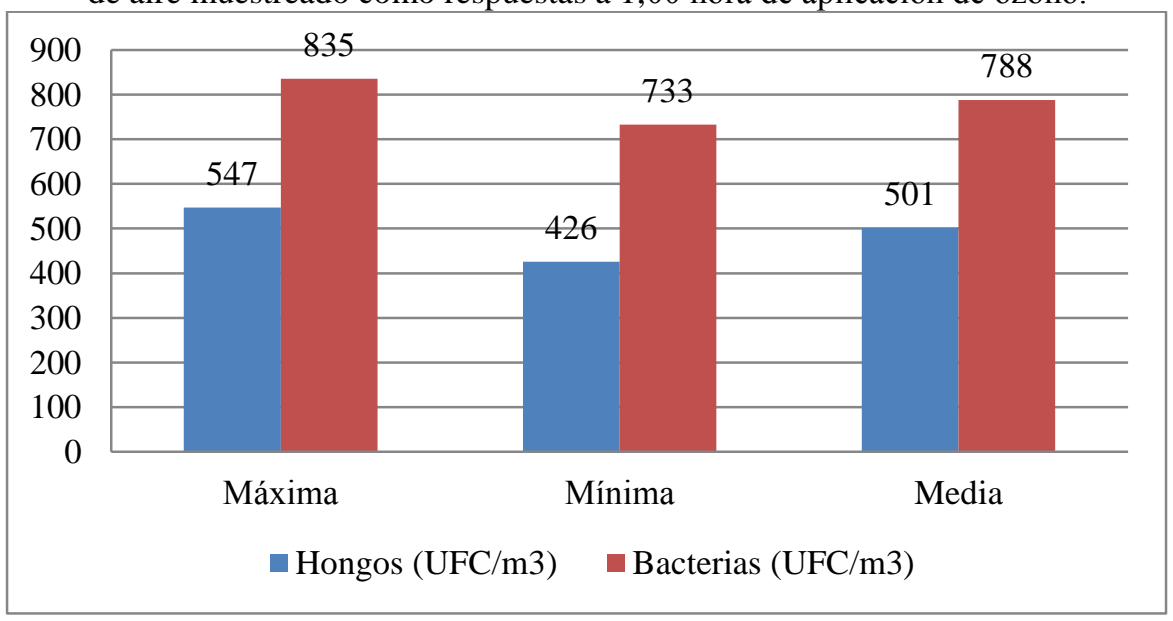


Figura No. 6. Concentraciones en Unidades Formadoras de Colonias por cada metro cúbico de aire muestreado como respuestas a 1,25 hora de aplicación de ozono.

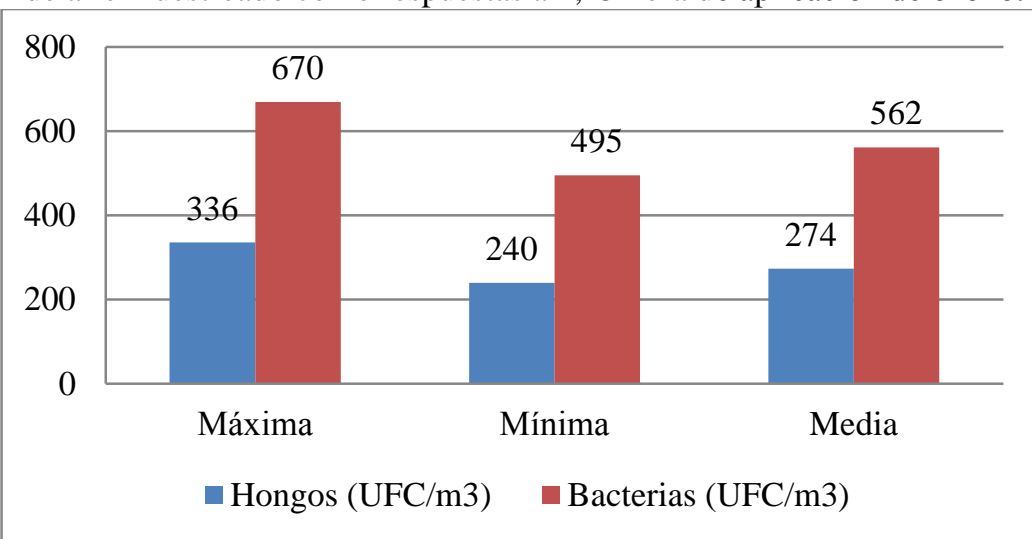

Figura No. 7. Concentraciones en Unidades Formadoras de Colonias por cada metro cúbico de aire muestreado como respuestas a 1,50 horas de aplicación de ozono.

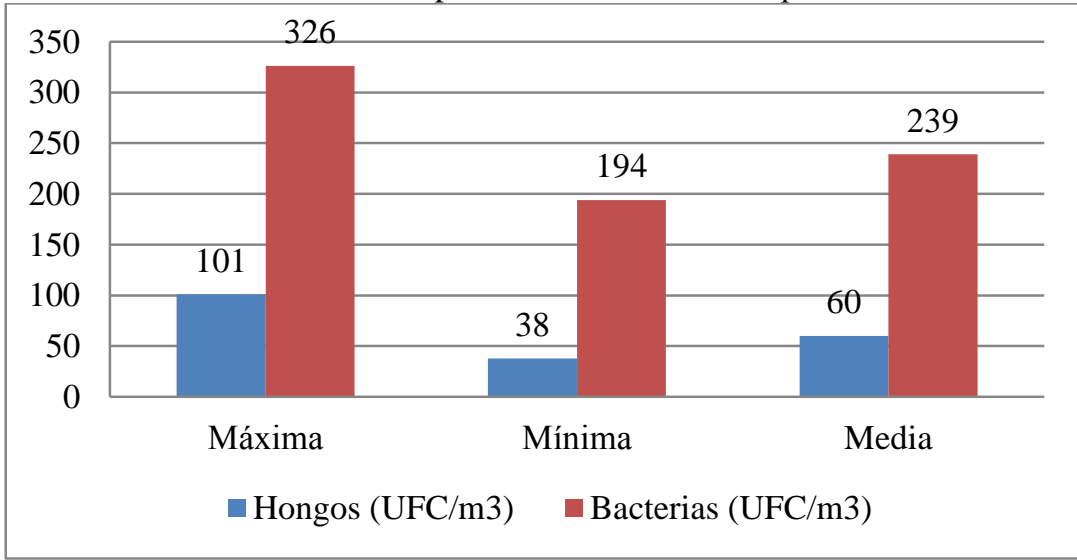

Figura No. 8. Concentraciones en Unidades Formadoras de Colonias por cada metro cúbico de aire muestreado como respuestas a 2,00 horas de aplicación de ozono.

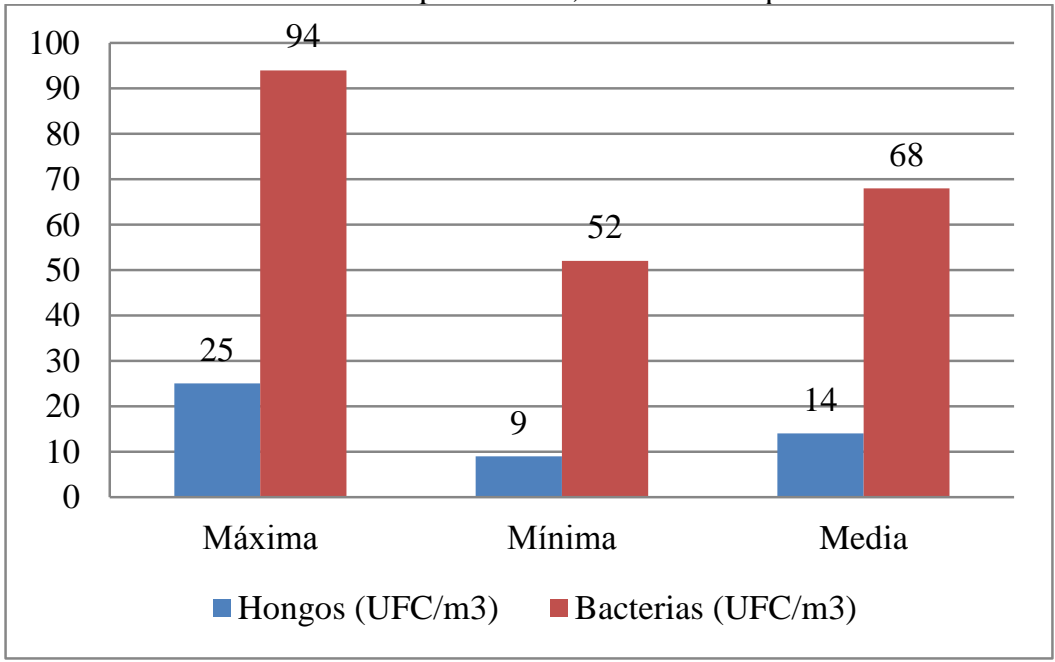


Figura No. 9. Concentraciones en Unidades Formadoras de Colonias por cada metro cúbico de aire muestreado como respuestas a 2,50 horas de aplicación de ozono.

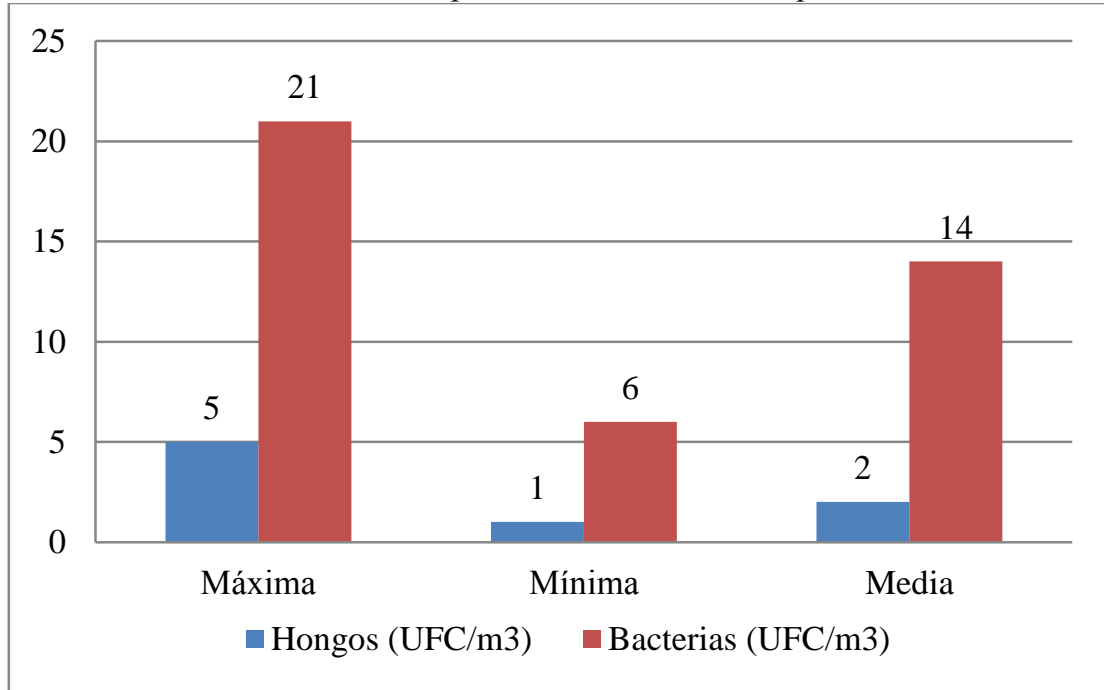

Figura No. 10. Concentraciones en Unidades Formadoras de Colonias por cada metro cúbico de aire muestreado como respuestas a 3,00 horas de aplicación de ozono.

En el gráfico de la Figura No. 11 se muestra de manera continua el comportamiento decreciente de la concentración de hongos y bacterias con relación al tiempo de aplicación de ozono.

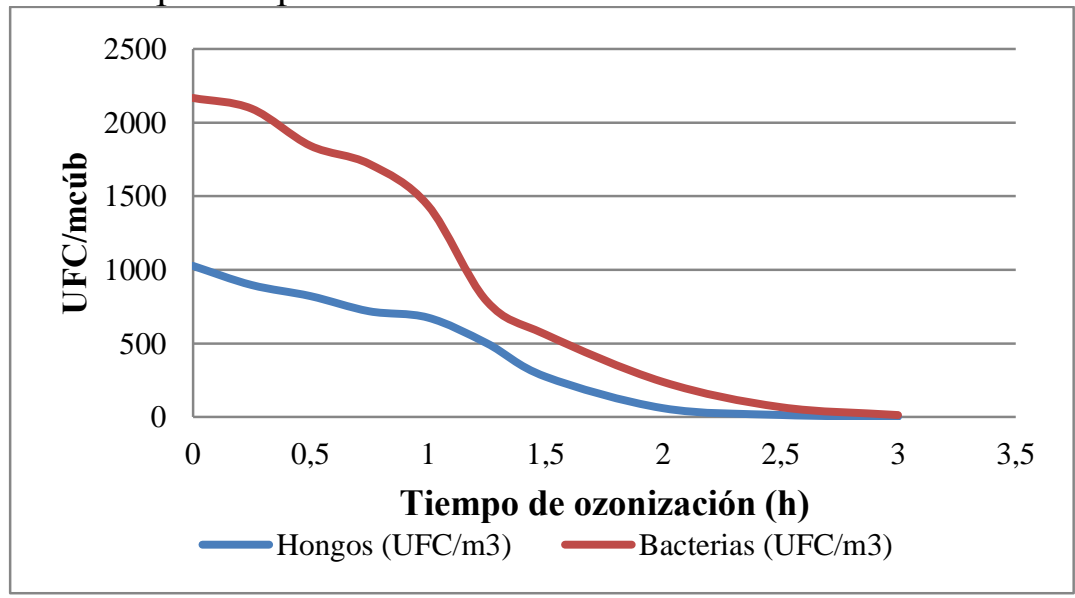

Figuras No. 11. Reducción de hongos y bacterias en el tiempo de ozonización

Se aprecia que teniendo en consideración el límite máximo establecido por la norma mencionada anteriormente, un tiempo de ozonización entre 1,25 y 1,50 horas es suficiente para que el aire del local bajo estudio pueda ser respirado sin que haya la amenaza de enfermedades en el tracto respiratorio de las personas que habitualmente se encuentran 
dentro de este. Sin embargo, al cabo de las 2 horas de aplicación, ya prácticamente es despreciable la presencia de hongos y bacterias.

\section{Conclusiones}

- Tanto hongos como bacterias presentes en el aire ambiente interior en la fábrica de productos lácteos "Quesos Latacunga", se encuentran en las cercanías o por encima del límite de $800 \mathrm{UFC} / \mathrm{m}^{3}$, que establece la normativa española UNE 100012 Higienización de sistemas (PROQUIMES S.A. División Ambiente, 2005).

- Los microorganismos mayoritarios identificados en el aire bajo estudio fueron Aspergillus sp., Penicilium, sp., Scopulariopsis sp., Fusarium sp. y, Cladosporium sp. La principales bacterias identificadas fueron Staphylococcus sp., Streptococcus sp., Bacillus sp., y Streptomyces sp. y, Enterobacter agglomerans.

- Al transcurrir una hora de aplicación de ozono la reducción de hongos, fue suficiente como para que su presencia cumpliera con el límite máximo establecido en la normativa considerada, sin embargo, eso no ocurre con las bacterias, necesitándose unos 25 minutos más para poder concluir lo mismo que para los hongos.

- Al alcanzar $2-2,5$ horas de ozonización del aire, la presencia de ambos tipos de microorganismos, mayoritariamente identificados, exhibieron valores de concentraciones despreciables, sinónimo de aire de buena calidad para la respiración de seres vivos.

\section{References:}

1. Ang, H. M., Tade, M. \& Wang, S. (2007). Volatile organic compounds in the indoor environment and photocatalytic oxidation: state of the art. Environmental International 33: 694-705.

2. Borrego, S. (2005). El edificio de archivo: su influencia en la contaminación microbiana ambiental, el biodeterioro y la salud del personal. IV Coloquio Iberoamericano del Papiro a la Realidad Virtual, Casa de las Américas. La Habana, Cuba.

3. Borrego, S., Pons, V. \& Perdomo, I. (2005). La influencia de la contaminación microbiana ambiental en el biodeterioro y la salud del personal. Las Bibliotecas y el Libro en el Siglo XXI. I Evento Científico-Técnico. La Habana, Cuba.

4. Elvis, A. M. \& Ekta, J. S. (2011). Ozone therapy: A clinical review. J Nat Sci Biol Med. 2011 Jan-Jun; 2(1): 66-70.

5. Engelberg (2014). Problems on air pollution. Third Congress on Air Pollution Control. San José, California.

6. Ministerio de la Industria Pesquera (1987). Análisis Ambiental. Método de Omeliansky. Análisis higiénico sanitario y ambiental. 
Métodos de ensayos microbiológicos. Norma Ramal de la Pesca NRP-201. La Habana, Cuba.

7. PROQUIMES S.A. División Ambiente (2005). Microbiología del aire. Cali, Colombia.

8. Rodríguez, F. J. (2003). Influencia del tratamiento con ozono en la purificación del agua. I Jornadas Técnicas de Ciencias Ambientales, Universidad de Burgos, Burgos, España.

9. Solórzano, J. E. \& Vera, D. V. (2014). El ozono y el control ambiental de microorganismos aerobios del área de producción del taller de procesos cárnicos. Escuela Superior Politécnica Agropecuaria de Manabí ESPAM - MFL, Calceta, Ecuador. 